\title{
O Ensino da Saúde Coletiva e a Escola Médica em Mudança: Um Estudo de Caso
}

\author{
Teaching Collective Health and Changes in \\ Medical Education: a case study
}

J人ßAVRAS-CHAVI':

- Eủucação Médica;

Esculas Médicas;

Merticina Social;

Ensino;

Aprendizagcru.

KEY-WÓRDS:

- Fiducation, Medical;

- Schools, Mactical;

- Collective I fealth;

- Teaching;

- I.centning

Recebido em: 16/06/2(102

Reencaninhadu em: $3(3 / 10 / 2003$

Aprovado em: U5/12/2003
Maria Alice A. Garci

Regina Célia N. Gomei Ana Carolina Z. Sacoman

Katia Cristina Costa ${ }^{3}$ Sabrina Rahal ${ }^{3}$
RESUMO

Este trabalho analisa a insergäo da Saúde Coletiva, na graduasca em medicina, enfocanda a reforma em pauta na PUC-Campinas. Ele relata esta reforma e, de modo mais detalhado, o processo ensino-aprendi" zagern junto à disciplina "Saúde da Comunidade: as siluaçżes de saúde" ministrada durante o primeiro ano do curso. As novas Dijetrizes Curriculares exigern mudancas estrutuais dos projetos pedagógicos, no sentido de gerar perfis profissionais mais adequados ao sistema de saúde e estratégias de aprendizagem ativa que fortalesam a articula fäo do ensino com o trabalho em difenentes cenários. Săo enfatizadus nestas diretrizes inúmeros conteúdos e práticas da Saúde Coletiva, kais como: a incorporaço do enfoque epidemiolb́gico na compreensäo dos determinantes sociais, culturais, psicológicus, ecológicos, éticos e

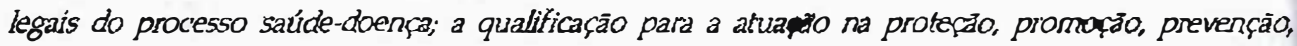
tratamento e reabilitapaio; o acompanhanento do processo de morter, conhecimentos para lidar criticamente com a dinânica do mercado de trabalho e com as pollticas de saúde; disposicăo para atuar em atividades de polftica e de planejamento; e a insercaso precoce e contínua na comunvidade e em todos os niveis dos serviços, sendo uma das cinco áreas do estágio curnicular obrigatorio. A educacão, estando integrada ao campo da Saúde Coletiva, Ihe confere responsabilidades éticas e um carater eminenternente Formador e problematizedor do "ser médico" de uma ciência de cuidado da vida.

\begin{abstract}
This sesearch analyzes the teaching of Collective Health during undergraduate medical school in light of a curricular refonn under way at the Catholic University in Campinas, Sado Paulo State, Brazil. The article reports in detail on the teaching/learning process in the course entitled "Community Health: health situations" during the first year of modical school. New curricular guidelines require structural changes in the teaching programs to promote more adequate physician profiles for the health system and active learning strategies that strengthen the link between the course and work in different health care seltings. These guidelines emphasize various contents and practices in Collective Health, including: the incorporation of an epidernialogical focus in the understanding of social, cultural, psychological, ecological, ethical, and legal determinants in the health/disease process; preparation of future physicians to act in protection, promotion, prevention, treatment, and rehabilitation; accompanying the process of dying; knowledge to deal critically with labor market dynamics and health policies; disposition to work with policy and planning activities; and early and ongoing participation in the community and at all levels of health services as one of the five areas of the mandatory curricular apprenticeship activities. To the extent that medical education is integrated into the field of Collective Health, it entails ethical responsibilities and intrinsically shapes and challenges the process of "beco ming a doctor" within this science focused an caring for the lives of others.
\end{abstract}




\section{INTRODUÇÃO}

Este trabalho discute a inserçāo da Saúde Coletiva na proposta curricular de reforma do Curso Médico da PUC-Campinas. Parte-se da premissa de que os currículos são dinâmi cos, devendo ser compartilhados contínua e sistematicamente entre seus pares (interna e externamente às faculdades $e$ instituições de ensino e serviços) e em resposta às necessidades postas pela sociedade. Cada escola tem sua própria históxia, mas considera-se importante criar espaços de diálogo que possibilitarāo a troca e o repensar das reformas.

Observa-se, atualmente, grande diversidade de modelos e conteúdos curriculares nas escolas médicas, o que parece dever-se em parte ao modo como cada escola insere-se no sistema de saúde. Esta inserçāo delineia os serviços docente-assistenciais como também o perfil dos professores e, conseqüütemente, o modus vivendi do currículo.

A discussão do papel da Saúde Coletiva neste processo é complexa, pois trata-se de uma área de conhecimento e prática interdisciplinar e multiprofissional que se apresenta em constante reordenamento; integra as dimensões: da produção e transmissão de conhecimentos, da política de formulação de propostas e organizaçāo corporativa e da operacionalização do planejamento, execução e a valiação destas políticas ${ }^{123}$.

O campo da Saúde Coletiva tem se inserido nos currículos médicos, por meio das disciplinas de Epidemiologia, Organizaçāo dos Serviços, Administração e Planejamento, Saúde do Trabalhador, Deontologia, Medicina Legal e estágios em unidades básicas de saúde ${ }^{2,4,5}$.

Atualmente, integrado a outras áreas da medicina [o campo de saúde coletiva?] responsabiliza-se pela inserção contínua dos alunos em comunidade e serviços, incorporando conteúdos relacionados: à abordagem integral das pessoas; tituição de alunos sujeitos de seu aprendizado; ao caráter social do fazer em saúde; à discussão do adoecer como processo bio-psico-sócio-cultural; ao fomento do trabalho em equipe multiprofissional; à constituição de modelos assistenciais voltados à ação competente e responsável e, em especial, a saúde da famúlia; à educação em saúde e à experimentação de ações de vigilância e outras de carăter coletivo ${ }^{25,6}$.

Faz-se necessário, entretanto, maior clareza e definição de seu papel perante a transformaçāo do ensino médico de graduação.

\section{A Saúde Coletiva e as reformas médicas}

A consolidação do Sistema Único de Saúde (SUS) e as reformas demandadas pela Lei de Diretrizes e Bases da Educaçāo (LDB) e diretrizes curriculares têm trazido inúmeros desafios para as escolas médicas. Destaca-se a constituição de currí- culos nucleares, horizontalizados, integrados interdisciplinarmente e a responsabilização compartilhada de modo crescente e amplo das escolas com o sistema de saúde. Priorizam-se os serviços públicos, sendo o Sistema Único de Saúde, em especial, os Programas de Saúde da Família, citados explicitamente, como demandantes de um novo perfil profissional ${ }^{7.8 .9}$.

Registra-se há décadas críticas e propostas de mudanças das escolas médicas, até entāo pouco efetivas e limitadas à inclusão de disciplinas e alterações de grades curriculares. Viabilizam-se, finalmente, reformas estruturais tanto dos projetos pedagógicos, no sentido de gerar perfis profissionais mais adequados ao sistema đe saúde, como estratégias de aprendizagem ativa que buscam fortalecer a articulação do ensino com o trabalho em diferentes cenários em que se concretiza o processo saúde-doença ${ }^{8,9,10,11}$.

Tais demandas trazem ao campo da Saúde Coletiva a necessidade de repensar seu papel junto à graduação das profissōes da saúde. Como discutido em recentes oficinas de trabalho da área (dezembro de 2002 e julho de 2003), esta reflexăo năo vinha sendo feita de modo coletivo e sistemático há 20 anos. Neste período, a Saúde Coletiva concentrou-se na produçăo de conhecimentos, na implementação da pós-graduação e em sua própria constituição como campo ${ }^{5,10}$.

Trata-se de campo científico recente, criado no Brasil em 1978, correspondendo em outros países à Saúde Pública e à Medicina Social. Tendo por objeto, de forma genérica, a saúde em sua dimensão coletiva; desdobra-se numa multiplicidade de objetos e conhecimentos que a tornam um campo teórico-metodoĺógico inter e transdisciplinar. Seu núcleo é constituído pela Epidemiologia, Ciências Sociais em saúde (sociologia, antropologia, política, economia, história), a Gestão e Planejamento, além de articular-se, enquanto campo, com as áreas da psicologia, filosofia, deontologia, geografia, ecologia e educação $0^{2,3}$.

A origem da Saúde Coletiva tem relações intrínsecas com a escola médica e, em especial, com os departamentos de Medicina Preventiva, Social ou de Saúde Pública. Estes, por sua vez, foram co-responsáveis pela constituição das reformas médicas (Medicina Comunitária e Integral) e contribuśram para a Reforma Sanitária brasileira que otiginou o Sistema Único de Saúde ${ }^{24}$.

Como produtos da Saúde Coletiva destacam-se ${ }^{2,3,4}$ :

- a interpretação crítica dos macroprocessos econômicos e políticos de concentração de renda e de poder, com exclusão social e a crise do Estado e das políticas sociais, que tornam-se visiveis por meio do baixo impacto da tecnologia junto às populações excluidas e do quadro de morbimortalidade; 
- a crítica ao poder médico, à linguagem e ao papel dos sujeitos e das instituiçôes e aos saberes dominantes, desmistificando-se a tecnologia e o saber;

- um modo de conhecer a realidade (ou o processo saúde-doença coletivo), aplicando-se a Antropologia Médica (explicaçōes culturais) e a Sociologia (explicaçōes sócio-econômicas);

- a contribuição para a eficácia dos sisternas por meio das teorias organizacionais, da análise institucional, da economia em saúde e do planejamento e administração;

- um modo de fortalecimento das pessoas por meio da participação social e da educaçāo em saúde, com ênfase não mais na crítica, mas na construção e na criação de alternativas e de respostas;

- a crítica à biomedicina e à ciência em geral que implicou no reconhecimento do caráter social e cultural do processo saúde-doença e numa "humanização por dentro" da medicina cientificamente instruída.

Em relação ao ensino de graduaçāo, resgatando as conclusōes da Oficina ocorrida em 1983, durante Congresso da ABRASCO, foi recomendada para as escolas médicas a inclusão de conteưdos das seguintes áreas: Epidemiologia, Ciências Sociais, Saúde e Trabalho, Administração e Planejamento em Saúde ${ }^{12}$.

De 1982 a 2002 foram realizados poucos encontros voltados à graduaçāo das profissōes da saúde, de caráter regional ou local, ou ainda, restrito aos núcleos constituintes da Saúde Coletiva. Na reunião de 1988, de docentes da área, foram citadas, enquanto dificuldades: a indefinição do objeto da Saúde Coletiva; o isolamento dos docentes e dos departamentose a "rejeição" do aluno ao social, reforçada pelo modelo assistencial e de ensino. Como estratégias para a superação destes impasses foram indicados: o trabalho trans-disciplinar; a inserção do ensino na prática com estudos e intervençōes sobre a realidade; a utilização de técnicas didáticas que permitissem a relação entre o enfoque individual e o coletivo; a escolha de conteúdos que possibilitassem ao aluno situar-se enquanto participante de um campo de conhecimentos em constante reestruturaçāo ${ }^{13}$.

Quanto ao ensino das Ciências Sociais registra-se a Oficina promovida pela ABRASCO em 1993, em Belo Horizonte. As conclusōes e dificuldades apontadas foram semelhantes as dos encontros anteriores, indicando-se que a raiz do problema estaria na dificuldade em se "wraduzir" a linguagem e os métodos das ciências sociais para a medicina. Pautada nas ciências naturais, a medicina torna os conteúdos sociais "descolados do sujeito", "pouco importantes", ou com pouca "aplicaçāo prática" na visāo dos alunos. Para a superaçāo destes limites propôs-se "buscar as mediaçōes entre o social e o bin lógico, entre as abordagens do indivíduo e as que se centram na sociedade" ${ }^{\prime 14}$.

A discussão feita pelo núcleo das Ciências Sociais indica que năo caberiam conhecimentos genéricos ou modelos de análise social, mas a sua aplicação à interpretação da socieda de, do cotidiano, da ação profissional e das questōes éticas políticas $^{14,15}$.

Desde então, desenvolveram-se importantes conhecimen tos e práticas com repercussðెes nos serviços e na formação: B consolidação do paradigma da Promoção da Saúde e a Vigilância em Saúde ${ }^{3}$; o Programa de Saúde da Família, como es tratégia para a reorganização do sistema ${ }^{7}$; as reflexōes sobre Saúde Pública, patrocinadas pela OPAS ${ }^{16,17}$; as experiências de Integração Docente Assistencial (IDA), em especial a critu ção da Rede IDA em 1985; os projetos UNI, em 1991 e a Rede UNIDA em $1995^{38,19}$; a articulação do CINAEM pelo conjunts das entidades médicas para avaliação do ensino médico ${ }^{1}$ : revigoramento da discussão da formação médica pela $\mathrm{ABE}$ e a definição das Diretrizes Curriculares para os cursos d área de saúde ${ }^{8,11}$.

Estas diretrizes representam avanço e fłexibilizaçāo n ensino da área, em contraposição aos currículos mínimos de finidos a partir da antiga LDB. Registra-se também o incenti vo conjunto dos Minisłérios da Educação eda Saúde, por mei do PROMED e da proposta mais recente de constituiçāo d Pólos de Educação Permanente, que visam o incentivo à mudanças na graduação e demais níveis das carreiras do profissionais da saúde ${ }^{9,20,23}$.

As tendências expressas na organizaçāo do Sistema d Saúde, na formação dos profissionais, os conceitos de apren dizagem ativa, a articulação dos conteúdos de vărias área disciplinares, as exigências de novas relaçס̄es entre instituł çōes formadoras, as instituiçōes prestadoras de serviços e usu ários organizados, impõem novos desafios ao ensino da Saú de Coletiva ${ }^{5}$.

As Novas Diretrizes Curriculares enfatizam inúmero conteúdos e práticas da Saúde Coletiva como: a incorporaçả do enfoque epidemiológico, populacional, a compreensão do determinantes sociais, culturais, comportamentais, psicológicos, ecológicos, éticos e legais do processo saúde-doença, es tabelecendo que a estrutura dos cursos tenha por um dos ei xos do desenvolvimento curricular as necessidades dos indi víduos e das populações; a qualificação para a atuaçāo na pró teção e promoção da saúde e na prevenção de doenças, beII como no tratamento e reabilitação dos problemas de saúde acompanhamento do processo de morrer; conhecimentos par lidar criticamente com a dinâmica do mercado de trabalho 
com as políticas de saúde; a disposição para atuar em atividades de política e planejamento; e a inserção, durante o estágio curricular obrigatório, em serviços qư possibilitem a aplicaşāo destes conteúdos ${ }^{8}$.

Como destacado nos documentos relativos aos Pólos de Educação Permanente, um processo de desenvolvimento da melhoria das condiçöes de ensino deve ser capaz de orientar a instituição para o seu auto-conhecimento e para o reconhecimento de suas potencialidades e desempenhos mas, principalmente, para garantir suficiente qualidade pedagógica para a formação superior de profissionais de saúde e para fortalecer o sistema onde irá atuar, destacando-se o compromisso com a ๓nsolidação do SUS e de seus princípios constitucionais ${ }^{21}$.

Propõem-se a responsabilização social e comunicação entre as escolas e a sociedade tendo por referência a capacidade de se dar resposta às necessidades da população, produzindo conhecimentos relevantes para a realidade de saúde, educação permanente dos profissionais e prestação de serviços de boa qualidade ${ }^{21}$.

De acordo com estas orientações, as estratégias de avaliação devem ser capazes de revelar o processo real de formaçāo vigente na escola, indo além das declaraçōes e propostas. Indir-se, também, que se construa institucionalmente a cooperaçà entre as escolas e o SUS, ou seja, que cada iniciativa, cada passo, cada projeto, constitua-se em fruto de um compromisso institucional, cumprindo o papel estratégico na mudança da formaçāo e do sistema, para construir capacidades, sensibilizar e mobilizar pessoas, repensar valores, objetos e relações ${ }^{20}$.

O relato da reforma da Faculdade de Medicina da PUCCampinas e sua discussāo visam a contribuír para o encaminhamento em direção a estas diretrizes governamentais.

\section{A Saúde Coletiva na reforma curricular da PUC- Campinas}

O curso de Medicina da PUC-Campinas implantou seu projeto de reforma curricular no ano de 2001, norteado pela nova LDB e incorporando as mudanças para o ensino médico ${ }^{22}$.

Tem por diretrizes: a formaçăo ético-humanista; a disposição e habilidade para a educação continuada; $a$ inserção do aluno na comunidade e serviços em todo o curso e a aptidāo para o gerenciamento e administraçāo em saúde.

Pretende constituir-se em um currículo flexivel, não mais centrado na transmissão de conteúdo, mas pautado na pedagogia da problematizaçāo (aprender a aprender), integrando árcas e disciplinas com aprofundamento crescente, superando a dicotomia entre estudo e trabalho.

Estrutura-se em quatro ciclos, sendo o primeiro composto for três semestres de introduçāo das bases morfofisiológi- cas da medicina por meio de casos-motivadores e sistemas; o segundo ciclo, também de três semestres, referentes às bases fisiopatológicas e clínicas dos ciclos de vida; o terceiro ciclo de ênfase clínica e, nos últimos dois anos, o internato.

A área da Saúde Coletiva perpassa estes ciclos buscando de modo integrado e com complexidade crescente propiciar ao aluno o conhecimento e sua aplicação prática. Tem como disciplinas e principais conteúdos:

- Saúde da Comunidade: situações de saúde $-1^{2}$ semestre

Territorialização; abordagem familiar; concepções do processo saúde-doença; situações e condicionantes do adoecer; perfis sócio-econômico, demográfico e de morbi-mortalidade

- Saúde da Comunidade: práticas de saúde $-2^{2}$ semestre

Conhecimento das lógicas dos diferentes sisternas e niveis de atenção; modelos assistenciais; controle e organizações sociais; trabalho em equipe multiprofissional

- Medidas de Saúde Coletiva $-2^{9}$ semestre

Indicadores de saúde e de condições de vida; sistemas, fontes e bancos de dados; Epidemiologia descritiva

- Processos de saúde-doença e prevenção - $3^{\underline{u}}$ semestre Estrutura epidemiológica; História natural e níveis de prevenção; Vigilância da saúde

- Saúde da Comunidade: o ambiente $-4^{2}$ semestre Vigilância sanitária; Saúde do trabalhador; Saúde ambiental; Educação em saúde.

- Epidemiologia analítica - $5^{9}$ ou $6^{9}$ semestres Método epidemiológico, medicina baseada em evidências, tipos de estudos, testes de hipóteses, validaçāo de testes diagnósticos

- Deontologia e Ética Médica

Ética das áreas médicas, Temas atuais em ética, Código de Ética Médica

- Internato - $9^{9}$ ao $12^{2}$ semestres - estágio de 6 semanas em perfodo integral

Inserçāo nas equipes de Saúde da Família realizando todas as atividades inerentes à ação médica: atenção individual no serviço, no domicilio ou equipamentos sociais; grupos terapêutico-educativos intra e extramuros; ações de vigilância; participação em projetos educativos e na educação permanente das equipes; atividades de cunho administrativo-gerencial.

\section{Relato das Atividades de uma Disciplina}

A disciplina "Saúde da Comunidade: as situações de saúde", inserida no primeiro semestre do curso, fundamental- 
mente, propiciar a vivência de situações reais de relacionamento do aluno com usuários, profissionais dos serviços de saúde e a própria comunidade ${ }^{23}$. Partindo desta vivência e integrando os conceitos básicos das Ciências Sociais e da Epidemiologia, objetiva:

1. Discutir as questões da medicina enquanto prática técnica e social.

2. Resgatar o papel do aluno e do médico enquanto profissional e cidadão.

3. Identificar a diversidade de condicionantes bio-psicosócio-cul turais do adoecer.

4. Reconhecer aspectos da estrutura social que interferem na saúde, como os relacionados à família, ao processo de urbanização e à estrutura de emprego.

5. Identificar a diversidade de conceitos e representaçōes relacionados à saúde e à doença.

6. Desenvolver habilidades na aproximação com as pessoas e as famf́lias.

7. Descrever as situaçães de saúde utilizando referenciais e instrumentais epidemiologicos.

8. Lidar com diferentes fontes de informação (entrevistas, registros de serviços médicos, mídia, informes epidemiológicos, internet, publicações).

9 Relacionar e buscar explicaçőes para os problemas levantados e observados.

10. Identificar $e$ indicar formas de superação destes problemas.

11. Desenvolver a habilidade da narrativa, em especial das situações de saúde.

Integranse durante o semestre (horizontalmente) com as seguintes disciplinas, cumprindo os objetivos $\mathrm{de}^{22,23}$ :

- Correlação Clínica e Bases Morfofisiológicas - permitir aos alunos conhecer e aproximar-se de casos reais nas familias correlatos aos casos motivadores; contribuir na construção dos casos.

- Bases de Apoio ao Aluno - trabalhar com questōes surgidas na prática cotidiana nos relacionamentos interpessoais nos diferentes cenários.

- Introduçăo à Metodologia - exercitar a problematização empreendendo um processo científico de busca de conhecimentos e de resignificação de conceitos; aplicação do método científico no desenvolvimento das atividades da disciplina: levantando problemas, indicação de hiṕteses para sua explicação e/ou resolução; trabalho de campo junto às fanulias, bairro e/ou por meio de dados secundários; análise deste material; elaboraçāo de relatório em forma de trabalho monográfico e preparo para apresentação.
Em relação ao processo ensino-aprendizagem, priviltz্̧ব) ando a ação do aluno, ora individual, ora em grupo, utilizam! se diferentes estratégias pedagógicas que permitam ampli a interação, a busca de conhecimentos e o questionamento Cada atividade é composta por três momentos: 1) de prepart indicação dos objetivos da atividade, levantamento de conha cimentos prévios, elaboração de roteiro para trabalho de cam po e dinâmicas; 2) de trabalho de campo: visitas, entrevistist observações da comunidade, famílias e equipamentos son ais; 3) de processamento das informações por meio da elab ração de relatớrios, apresentaçāo e discussão em grupo.

As atividades da disciplina podem ser resumidas em qus tro componentes:

a) Avaliação diagnóstica e construção do perfil da clasi é aplicado um instrumento (a carta $\mathrm{e}$ o pedido) que permi traçar o perfil da classe (idade, sexo, procedência, área medicina com a qual se identifica; presença de médicos família; acesso à informática; anos de curso pré-vestibulự atividades extracurriculares) e conhecer as expectativas di alunos perante o curso e seu entendimento das habilidades comportamento necessários ao exercício da profissão. São in troduzidos conhecimentos relacionados ao mercado e ao $\mathrm{p}$ cesso de trabalho médico, a noção de perfil e habilidades organização de dados, as formas de coleta, a importância d informaçōes quantitativas e qualitativas (e subjetivas) para। conhecimento das "situaçỏes" (no caso de uma classe de al nos de medicina).

b) Discussảo dos conceitos de saúde e de doença: indin se antecipadamente a leitura de textos (como $A$ Doença, de Berlingüer e Saber Cuidar: ética do humano, de Leonardo Boff) durante a aula é a realizada a discussão, numa primeira etré pa, em pequenos grupos, utjlizando objetos intermediáriw Esta estratégia permite a participação de todos os alunos e discussão não só de colocaç̋̃es das leituras, mas de conceit anteriores e reconstrurdos no proprio grupo. Amplia-se a ticidade e acrescem-se noçōes e inferências processuais, su jetivas e estéticas do conceito de saúde-doença. Discute-se: complexidade dos condicionantes s6́cio-econômicos, culturaisi biológicos e psíquicos do viver e do adoecer que têm marca individuais, singularidades e universais.

c) Visita impressionista ao território (regiāo do Distriti de Saúde Noroeste de Campinas/SP): têm por objetivos: pno piciar ao aluno o conhecimento da regiāo onde se localiza! Campus II da PUC-Campinas; introduzir as noções de perfí epidemiológicos e situaçōes de risco; possibilitar o levantă mento, análise e organização de dados populacionais e pro blematizar as situações de saúde, de doença e de morte, alér das possiveis formas de superação. O preparo do trabalho di 
campo envolve a disscussão de conceitos com indicaçăo bibliográfica prévia, elaboração do roteiro de visita, do mapa e o levantamento de informaçōes demográficas, sócio-econômicas e de morbi-mortalidade, obtidas de fontes secundárias. realizada uma visita impressionista de apresentaçāo do terrilório, buscando descrever: características gerais, histórico do desenvolvimento e serviços de saúde da regiāo; dinâmica po. pulacional; aspectos geográficos e ambiente físico, condiçōes de urbanização e características das moradias; saneamento básico, serviços oferecidos à populaçåo e equipamentos sociais.

d) Visita as famílias: é designada pelos agentes de saúde uma familia para cada dupla, ou trio de alunos..Após a apresentação pelo docente, os alunos realizam as visitas as famílias. Como as demais atividades, há a preparaçāo por meio da leitura e discussāo temática da abordagem familiar; o estudo do roteiro com informaçōes demográficas, sócio-econômicas (escolaridade, ocupação e renda), de moradia, saneamento, morbidade e utilização de serviços de saúde; assim como questōes abertas acerca de hábitos, atividades culturais, representaçōes sobre o processo saúde-doença, problemas encontrados na comunidade e possiveis solu̧çōes. Objetiva-se a habilidade para o diálogo com a família. Após as visitas é construido um quadro com os resultados e o relato dos aspectos considerados marcantes. Os resultados são devolvidos para as equipes dos serviços. Nas avaliações da disciplina esta atividade é considerada a mais gratificante.

e) Relatório final: para a elaboração da monografia cada equipe de alunos escolhe uma "situação" presente no território (estrutura familiar, saneamento, condiçōes de moradia, trabalho e ocupação, lazer, etc) referenciando-se ao método científico.

Estas atividades contam também com a participaçāo de monitores da disciplina e de agentes de saúde das equipes das Unidades Básicas de Saúde locais.

\section{As Possibilidades do Campo da Saúde Coletiva na Graduação Médica}

Tradicionalmente os alunos de medicina têm contato com as serviços e pacientes somente a partir do $3^{\mathrm{g}}$ ano (em alguzhas escolas só no internato) e no interior do ambiente hospitalar, aspectos que decorrem da dicotomia entre teoria e prática; da divisāo entre disciplinas básicas e profissionalizantes e da valorização do modelo hospitalocêntrico ${ }^{2,4}$.

A inserção precoce em serviços e comunidade tem funcionado como uma estratégia fundamental para a reversão desta estrutura, pois implica no compromisso da escola com estes serviços e a aproximaçāo do processo de educar de seu caráter sociocultural. Esta açăo educativa possibilita o rompimento com o modelo clássico de ensino centrado na relação professor-aluno para uma triangulação docente-equipe/aluno/usuário; exige um descentramento dos conteúdos tradicionais e amplia o cenário da sala de aula para o cotidiano do trabalho ${ }^{5,6224}$.

Em contato com as familias, equipamentos sociais e comunidade, possibilita-se aos alunos: a apreensão da diversidade de situaçōes e representaçōes acerca do processo saúdedoença e o reconhecimento da determinaçäo social e sua relação com os cenários individuais e singulares do adoecer para além do biológico, em seus condicionantes sociais, culturais, econômicos.

Acontece, como indicado nas Diretrizes Curriculares, a experimentação da inter-relação entre colegas, com profissionais e usuários, os primeiros passos para a introjeção de papéis enquanto estudantes de medicina e futuros médicos ${ }^{8}$.

Metodologias ativas de ensino-aprendizagem ligadas ao trabalho e outras vivências cotidianas permitem ao ensino cumprir seu papel perspícuo de humanização. A interaçāo e a mediação com diferentes sistemas simbólicos (a cultura) implicam na "tomada de posse" e na apropriação dos planos de ação (a internalização), no lugar da absorção passiva de conhecimentos ${ }^{6,25,26}$

Por sua vez, na percepçãọ da experiência o homem opera em sua máxima plenitude e o seu comportamento é construtivo; nem sempre [este comportamento?] será convencional, ou conformista, mas individualizado, e também socializado ${ }^{27}$.

Evidencia-se que a maturidade necessária para o cumprimento destes papéis é diferenciada entre os alunos, mas abrem-se caminhos para a superação de limites individuais $e$ a busca de uma ação responsável e humana. As oportunidades e situações de relacionamento parecem permitir ultrapassar o "dever ser" moral de exemplos idealizados, para a discussão efetiva de problemas reais que são inerentes ao cotidiano do "fazer" em saúde ${ }^{28}$.

Ao educador e ao educando apresenta-se nos serviços uma relação dialógica que exige desconstruir e problematizar o cotidiano, ou seja, tornar-se "consciente", fato que se dá por meio da intencionalidade, não só em relação a objetos (ou a outras pessoas), mas também a si mesmo ${ }^{29}$.

Como discutido por L'Abbate ${ }^{28}$, o agir competente de um profissional de saúde exige saber fazer bem técnica, politicamente e sob a mediação da ética. Para isto, “não basta saber; é preciso também querer; e nāo adianta saber e querer, se não se tem a percepçāo do dever e não se tem poder para acionar os mecanismos de transformação nos rumos da instituição." Trata-se de um compromisso que faz necessária "a adesão, a partir da escolha do sujeito a uma certa maneira de agir, a um certo caminho para a ação". 
O referencial da Educação integra o campo da Saúde Coletiva, tanto como modelos instrucionais que baseiam o processo ensino-aprendizagem, como no ato profissional seja individual, seja coletivo ${ }^{1,628}$.

O ensino da Saúde Coletiva apresenta, desta forma, um carăter predominantemente formativo. Suas implicações 'sócio-psico-éticas' lhe trazem a responsabilização com comportamentos, atitudes e habilidades e a constituição de um cotidiano que responda a estes princípios. $\mathrm{Na}$ aprendizagem em serviços ou na comunidade a ação educacional de caráter triangular docente-equipe/aluno/usuário exige do docente formação técnica e política, e dos alunos um processo autodirigido de aprendizagem, o que favorece o desenvolvimento integral. Cabe a estes um papel ativo desde o planejamento até a avaliação de seu processo de aprendizagem. O sentir, o pensar e o agix, de modo mais efetivo e afetivo, conduz a uma postura de maior responsabilidade ${ }^{5,6,24,30}$.

Para além de problemas genéricos, o ensino no cotidiano do trabalho profissional implica em práticas e conhecimentos relacionados ao cuidar, tais como: ouvir, ter bom senso, respeito e confiança. Tais situações possibilitam a mudança da tendência de "coisificação" do indivíduo (aluno e paciente) que processa-se no ensino tradicional, onde não se tem história, nem passado, nem futuro, mas um trabalho com o fim em si mesmo, como uma técnica protocolar pré-determinada que exclui a realidade $e^{6,30}$.

Outra importante discussão relacionada ao ensino da Saúde Coletiva é a de que as situações vivenciadas pelos alunos ก̃̃o devam ser criadas artificialmente ou de modo isolado no interior das escolas, mas que estejam integradas, prioritariamente, ao sistema público de saúde. Isto exige parcerias, bem como o compromisso com necessidades sociais, continuidade, responsabilizaçāo e vínculo, cumprindo-se as diretrizes do SUS ${ }^{6}$.

Temos um grande desafio pela frente que não limita-se a uma disciplina ou uma área da medicina, mas a integraçāo com as diferentes profissões da saúde.

A intenção deste relato de experiência docente, apesar de limitado a uma escola, é a de possibilitar a discussão do caráter das reformas de ensino. Necessitamos ultrapassar a inserção de uma determinada área ou conteúdo, lidando com a construção de sujeitos num processo cotidiano de humanização: de compreensão de si mesmo, para a percepção do que o cerca e o encaminha para a globalidade e a integração ${ }^{27}$.

Buscando contribujr para o rompimento dos 20 anos de silêncio das questões ligadas à inserção da Saúde Coletiva no ensino da graduação das profissões de saúde, a intenção foi criar espaços de dúvidas e de reflexão neste momento proficuo de reformas das escolas e de construção de um projeto nacional de melhoria das condiçōes de ensino e prestação serviços da saúde em direção à vida.

\section{REFERÊNCIAS BIBLIOGRÁFICAS}

1 Paim JS. Marco de referência para um programa de edi cação continuada em Saúde Coletiva. Rev Bras Educ Mił 1993; 17: 1-44.

2. Canesqui AM. As ciência sociais, a saúde e a saúde colet va. In: Canesqui AM (org). Dilemas e desafios das ciência sociais na Saúde Coletiva. São Paulo, Rio de Janeira Hucitec, ABRASCO; 1995.

3. Stotz EN. A saúde coletiva como projeto científico: teori problemas e valores na crise da modernidade. In: Canesq AM (org). Ciências sociais e saúde. São Paulo: Hucite: ABRASCO; 1997 p. 273-84.

4. Costa NR. Ciências Sociais e saúde: considerações subre nascimento da saúde coletiva no Brasil. Saúde Debate 1992 36: 58-65.

5. Marsiglia. RG, Feuerwerker LC, Carneiro Jr N. Relatóri da Oficina Nacional de Trabalho sobre o ensino de Saúd Coletiva na graduação médica. São Paưlo: Faculdade d Ciências Médicas da Santa Casa de São Paulo; 2002.

6. Garcia MAA. Saber, agir e educar: o ensino-aprendizager em serviços de saúde. Interface 2001; 8: 89-100.

7. Brasíl. Ministério da Saúde. Saúde da Família: uma estra tégia de organização dos serviços de saúde. Documen! preliminar. Brasília (DF): MS/SAS/DAPS; 1996.

8. Brasil. Ministério da Educação. Conselho Nacional Educação. Diretrizes curriculares nacionais do Curso Graduação em Medicina. Resolução CNE/CNS de ?/11 2001. Brasília (DF): MEC/Câmara de Educação Superio do Conselho Nacional de Educação; 2001a.

9. Brasil. Ministério da Saúde. Programa de incentivo a mu danças curriculares no Curso de Medicina - PROME Brasília: MS/Secretaria de Políticas de Saúde; 2001b.

10. Campos JJB et al. Relatório da Oficina de Trabalho: Saúd Coletiva e graduação das profissões da saúde à luz d diretrizes curriculares nacionais, realizado durante o VI Congresso Brasileiro de Saúde Coletiva. Brasília (DF Redeunida; 2003.

11. Comissão Interinstitucional Nacional de Ensino Médic Preparando a transformação da Educação Médica bray leira. Projeto CINAEM III FASE. Relatório 1999-2000. Ri: de Janeiro: CINAEM; 2000.

12. Associação Brasileira de Pós-graduação em Saúde Colekt' va. Ensino da Saúde Pública, Medicina Preventiva e Sou al no Brasil, 3. Rio de Janeiro: Abrasco; 1984. 
13. Faculdade de Ciências Médicas/Santa Casa. Reunião dos Departamentos de Medicina Preventiva e Social de SP.São Paulo: Departamento de Medicina Social/FCM/Santa Casa; 1988. 20p.

14. Associação Brasileiro de Pós-graduação em Saúde Coletiva. Documento Preliminar da Oficina: Ensino de Ciências Sociais. I Encontro Brasileiro de Ciências Sociais em Saúde. Belo Horizonte (MG): UFMG/Abrasco; 1993. 14p.

15. Adorno RCF. A escola, o campo, a diversidade, o jogo: as ciências sociais e as trilhas do ensino em uma instituição de saúde pública. In: Canesqui AM (org). Dilemas e desafios das ciências sociais na Saúde Coletiva. São Paulo, Rio de Janeiro: Hucitec, ABRASCO; 1995.

16. Organizaçāo Panamericana de Saúde /Organização Mundial de Saúde. As transformações da profissão médica e sua influência sobre a educaçāo médica. Washington D.C. (US): OPAS/OMS; 1992. 15p.

17. Nájera E. La salud publica, una teoria para una practica; se precisa su reconstruccion? In: Situação e tendências da saúde pública na regiāo das Américas. Washington (US): OPAS; 1991. p.123-32.

18. Araujo EC, Teixeira CF, Rangel ML. Relação ensino-serviço-comunidade: a contribuição da rede IDA. Saúde em Debate, 1995, 49-50: 88-94.

19. Marsiglia RG. Relação ensino/serviços: dez anos de integração docente-assistencial (IDA) no Brasil. São Paulo, Salvador: Hucitec, ISC; 1995. 116p.

20. Brasil. Ministério da Saúde. Seminário: incentivos às mudanças na graduação das carreiras da saúde. Brasília (DF): Secretaria de Gestāo do Trabalho e da Educaçăo na Saúde/Departamento de gestão da Educaçãona Saúde; 2003a.

21. Brasil. Ministério da Saúde. Caminhos para a mudança da formação e desenvolvimento dos profissionais da saúde: diretrizes para a açăo política para assegurar Educação Permanente no SUS. Brasilia (DF): Secretaria de Ges- tão do Trabalho e da Educação na saúde/Departamento de gestão da Educação na Saúde; 2003b.

22. Pontifícia Universidade Católica de Campinas. Projeto pedagógico da Faculdade de Medicina. Campinas (SP): Faculdade de Medicina/CCV/PUC-Campinas; 2001.

23. Pontifícia Universidade Católica de Campinas. Plano de curso: Disciplina Saúde da comunidade: as situações de saúde. Campinas (SP): FCM/PUC-Campinas; 2001.

24. Hossne WS. Relaçāo professor-aluno: inquietaçōes, indagaçōes, ética. Rev Bras Educ Méd 1994; 18: 75-81.

25. Oliveira MK. Vygotsky: aprendizado e desenvolvimento, um processo sociohistórico. 2 ed. São Paulo: Scipione; 1995. 111p.

26. Góes MC. A natureza social do desenvolvimento psicológico. Pensamento e linguagem: estudos na perspectiva da psicologia soviética. São Paulo: Papirus; 1991 p. 17-31. (Caderno CEDES, 24).

27. Gomes RCN. Formação humanista do médico: contribuiçōes para uma reflexão na concepção de Carl Rogers. [dissertação] Campinas (SP): Faculdade de Educação, Universidade de Campinas; 2002. 168p.

28. L'Abbate S. Comunicaçāo e educação: uma prática em saúde. In: Merhy EE, Onocko R (org). Agir em saúde: um desafio para o público. São Paulo: Hucitec; 1997 p.267-92.

29. Freire P. Pedagogia do oprimido. 13 ed. Rio de Janeiro: Paz e Terra; 1983.

30. Boff L. Saber Cuidar: ética do humano. Petrópolis (RJ): Vozes; 1999.

\section{Endereço para Cortespondência:}

Maria Alice Amorim Garcia

Rua Américo de Campos, 416, Cidade Universitária

Campinas/SP-

CEP:13083-040

E-mail: millas@iłexxa.com.br 